\title{
Binding Domains of Stimulatory and Inhibitory Thyrotropin (TSH) Receptor Autoantibodies Determined with Chimeric TSH-Lutropin/Chorionic Gonadotropin Receptors
}

Yuji Nagayama, Harry L. Wadsworth, Diego Russo, Gregorio D. Chazenbalk, and Basil Rapoport Thyroid Molecular Biology Unit, Veterans Administration Medical Center, San Francisco; and University of California, San Francisco, California 94121

\begin{abstract}
We examined the relative effects of thyrotropin (TSH) and TSH receptor autoantibodies in the sera of patients with autoimmune thyroid disease on three TSH-lutropin/chorionic gonadotropin (LH/CG) receptor extracellular domain chimeras. Each chimera binds TSH with high affinity. Only the chimera with TSH receptor extracellular domains ABC (amino acids 1-260) had a functional (cAMP) response to thyroid stimulatory IgG. The chimeras with TSH receptor domains CD (amino acids 171-360) and DE (amino acids 261-418) were unresponsive. The lack of response of the chimera with TSH receptor domains DE was anticipated because it fails to transduce a signal with TSH stimulation, unlike the other two chimeras. A different spectrum of responses occurred when the TSH-LH/ CG chimeras were examined in terms of autoantibody competition for TSH binding. IgG with TSH binding-inhibitory activity when tested with the wild-type TSH receptor also inhibited TSH binding to the chimera with TSH receptor domains DE. Dramatically, however, these IgG did not inhibit TSH binding to the chimera with TSH receptor domains CD, and had weak or absent activity with the chimera with TSH receptor domains $A B C$. Chimeras with TSH receptor domains $A B C$ and $D E$ were equally effective in affinity-purifying IgG with thyroid-stimulatory and TSH binding-inhibitory activities. Nonstimulatory IgG with TSH binding-inhibitory activity inhibited the action of stimulatory IgG on the wild-type TSH receptor, but not with the chimera containing TSH receptor domains ABC. In summary, TSH receptor autoantibodies and TSH bind to regions in both domains $A B C$ and $D E$ of the TSH receptor extracellular region. Stimulatory and inhibitory TSH receptor autoantibodies, as well as TSH, appear to bind to different sites in domains $\mathrm{ABC}$, but similar sites in domains DE, of the receptor. Alternatively, TSH and the different TSH receptor antibodies bind with differing affinities to the same site in the $A B C$ region. ( $J$. Clin. Invest. 1991. 88:336-340.) Key words: thyrotropin • receptor $\cdot$ autoantibodies
\end{abstract}

Address correspondence and reprint requests to Dr. Yuji Nagayama, Veterans Administration Medical Center, Thyroid Molecular Biology Unit (111T), 4150 Clemont Street, San Francisco, CA 94121.

Received for publication 5 February 1991 and in revised form 3 April 1991.

The Journal of Clinical Investigation, Inc.

Volume 88, July 1991, 336-340

\section{Introduction}

Autoantibodies against the thyrotropin (TSH) ${ }^{1}$ receptor (1) can stimulate thyroid cell function and cause hyperthyroidism in Graves' disease. More uncommonly, nonstimulatory antibodies may inhibit TSH binding and cause hypothyroidism in Hashimoto's thyroiditis. The literature concerning thyroidstimulatory and TSH binding-inhibitory antibodies is confusing, partly because of the different methods available for their assays. The assay for thyroid-stimulatory IgG (TSI) measures a functional response in cultured thyroid cells, generally an increase in cellular cAMP generation $(2,3)$. More commonly used is an assay which measures the ability of patients' IgG to compete for TSH binding to the TSH receptor (4). This TSH binding inhibition (TBI) assay does not discriminate between thyroid stimulatory antibodies and nonstimulatory antibodies that also inhibit TSH binding. There is a relatively weak correlation between these two assays when they are used to test panels of TSH receptor autoantibodies, probably because of the presence of both stimulatory and inhibitory TSH receptor antibodies in the same serum sample $(1,5-7)$.

There is little information at the molecular level regarding the domain(s) on the human TSH receptor to which thyroidstimulatory and TSH binding-inhibitory autoantibodies bind, and the relationship between these domains and the TSH binding site. The recent molecular cloning of the human TSH receptor (8-11) now permits analysis of these issues. The TSH, lutropin/chorionic gonadotropin (LH/CG) $(12,13)$ and follicle-stimulating hormone (14) receptors are structurally-related members of a subfamily of guanine nucleotide binding regulatory $(G)$ protein-coupled receptors, distinguished by their large extracellular domains. In recent studies, we have divided the 418 amino acid TSH receptor extracellular region into five domains (A, B, C, D, and E). The substitution of these domains, singly or in combination, with the homologous domain(s) of the LH/CG receptor has created a series of TSHLH/CG receptor extracellular domain chimeras $(15,16)$. Data obtained with these chimeras reveal that the TSH binding site includes segments spanning the entire extracellular region of the receptor. Three partially overlapping regions, domains $\mathrm{ABC}$ (amino acids 1-260), $\mathrm{CD}$ (amino acids 171-360), and DE

1. Abbreviations used in this paper: $\mathrm{CHO}$, Chinese hamster ovary; LH/ CG, lutropin/chorionic gonadotropin; R, receptor; TBI, TSH binding inhibition; TSH, thyrotropin; TSI, thyroid-stimulatory IgG. 
(amino acids 261-418), can each confer high affinity TSH binding (Fig. 1). Because high affinity TSH binding indicates correct folding of the globular protein, and because of the importance of protein conformation in antibody recognition (17, 18), we used these TSH-LH/CG receptor chimeras to localize the domains on the TSH receptor that interact with the stimulatory and inhibitory antibodies in the sera of patients with autoimmune thyroid disease.

\section{Methods}

Serum samples and IgG preparations. We selected IgG from 15 patients with autoimmune thyroid disease to provide a broad range of TSI and TBI activity. IgG stimulatory activity was measured as described below, using hypotonic medium containing $1 \mathrm{mg} / \mathrm{ml} \mathrm{IgG}$ and Chinese hamster ovary (CHO) cells stably expressing the wild-type TSH receptor. Stimulatory dose-response curves with the majority of IgG used in this study $(0.001-1 \mathrm{mg} / \mathrm{ml}$; data not shown) revealed log-linear dose responses up to $1 \mathrm{mg} / \mathrm{ml}$, the concentration used in the study. However, these data do not exclude the possibility of antibody heterogeneity (both TSI and TSH inhibitory IgG) in the same serum sample. Four of these sera contained TSH binding-inhibitory IgG without TSI activity. TBI activity was measured as described below. As negative controls, we used IgG from three normal individuals with neither TSI nor TBI activity. IgG was purified from the sera by DEAE-Affigel blue column chromatography (Bio-Rad Laboratories, Richmond, CA), followed by dialysis against $\mathrm{H}_{2} \mathrm{O}$. The concentration of IgG in solution was calculated by adsorption at $280 \mathrm{~nm}$.

Thyroid stimulatory IgG assay. Clonal or pooled clones of $\mathrm{CHO}$ cells stably expressing the wild-type human TSH receptor (8) or TSHLH/CG receptor extracellular domain chimeras (15) were cultured in 24-well culture plates (Costar Corp., Cambridge, MA) in Ham's F12 medium supplemented with $10 \%$ fetal calf serum, $100 \mathrm{U} / \mathrm{ml}$ penicillin, $40 \mu \mathrm{g} / \mathrm{ml}$ gentamicin, $2.5 \mu \mathrm{g} / \mathrm{ml}$ fungizone, and $400 \mu \mathrm{g} / \mathrm{ml} \mathrm{G} 418$ (Geneticin; Gibco Laboratories, Grand Island, NY) at $37^{\circ} \mathrm{C}$ in an atmosphere of $95 \%$ air-5\% $\mathrm{CO}_{2}$. At confluence, the cells were rinsed once with $\mathrm{NaCl}$-free $\mathrm{HBSS}$, pH $7.4(5 \mathrm{mM} \mathrm{KCl}, 1.3 \mathrm{mM} \mathrm{CaCl}, 0.4 \mathrm{mM}$ $\mathrm{MgSO}_{4}, 0.34 \mathrm{mM} \mathrm{Na}_{2} \mathrm{HPO} 4,0.44 \mathrm{mM} \mathrm{KH}_{2} \mathrm{PO}_{4}$, and $0.1 \%$ glucose), supplemented with $20 \mathrm{mM}$ Hepes, and then incubated with IgG (1 $\mathrm{mg} / \mathrm{ml}$ ) in NaCl-free HBSS supplemented with $20 \mathrm{mM}$ Hepes, $0.4 \%$ BSA, and $1 \mathrm{mM}$ 3-isobutyl-1-methylxanthine. Incubations were for $2 \mathrm{~h}$ at $37^{\circ} \mathrm{C}$ in air. Cyclic AMP released into the medium was measured by radioimmunoassay (19). TSI activity (determined in duplicate or triplicate, as described in the text) was expressed as a percentage of the mean value of three normal IgG included as controls in each experiment. Values $>2$ SD above the mean of the normal IgG were regarded as positive. In experiments to evaluate the effect of TSH binding-inhibitory antibodies on TSI activity, inhibitory IgG or pooled normal IgG (final concentration of $0.5 \mathrm{mg} / \mathrm{ml}$ ) was added to IgG with thyroidstimulatory activity (final concentration of $0.5 \mathrm{mg} / \mathrm{ml}$ ).

TSH binding inhibition assay. The assay was performed as previously described (6) with minor modifications. Bovine TSH $(\sim 30$ $\mathrm{U} / \mathrm{mg}$ protein) was radiolabeled with the Bolton-Hunter reagent (New England Nuclear, Boston, MA). CHO cells expressing the wild-type TSH receptor or TSH-LH/CG receptor chimeras were cultured in 24 well plates. Before use in the assay, the cells were rinsed three times with $\mathrm{NaCl}$-free HBSS containing $250 \mathrm{mM}$ sucrose and $0.25 \%$ BSA. Incubations were for $2 \mathrm{~h}$ at $37^{\circ} \mathrm{C}$ in air, in the same buffer supplemented with $\sim 10,000 \mathrm{cpm}{ }^{125} \mathrm{I}-\mathrm{TSH}$ and $1 \mathrm{mg} / \mathrm{ml} \mathrm{IgG}$. TBI values were expressed as follows: [ 1 - (radioactivity of test IgG/radioactivity of normal IgG or assay buffer)] $\times 100(\%)$. Values $>2$ SD above the mean of three normal IgG included in each experiment were defined as positive.

IgG affinity purification with chimeric receptors. $\mathrm{CHO}$ cells expressing chimeric receptors (or, as a control, the plasmid ${ }_{p} \mathrm{SV}_{2} \mathrm{NEO}$ ) in 100 $\mathrm{mm}$ diameter culture dishes were rinsed three times with $\mathrm{NaCl}$-free
HBSS with $250 \mathrm{mM}$ sucrose and $0.25 \% \mathrm{BSA}$, and $4 \mathrm{ml}$ of IgG $(1 \mathrm{mg} /$ $\mathrm{ml}$ ) in the same buffer was added. After incubation for $2 \mathrm{~h}$ at $37^{\circ} \mathrm{C}$, the medium was aspirated and the cells were quickly rinsed three times with ice-cold phosphate-buffered saline. Bound IgG was eluted by incubating the cells with $4 \mathrm{ml}$ of $0.1 \mathrm{M}$ glycine-HCl, pH 2.5 (30 min at room temperature with intermittent rocking). The solution containing IgG desorbed from the cells was neutralized with $1 \mathrm{ml} 1 \mathrm{M}$ Tris- $\mathrm{HCl}$, pH 7.5, centrifuged for $20 \mathrm{~min}$ at $10,000 \mathrm{~g}$ to remove cell debris, and dialyzed against $\mathrm{H}_{2} \mathrm{O}$. The IgG, concentrated $\sim 15$ times using a Speed-Vac (Savant Instruments, Fullerton, CA), was used in TSI and TBI assays with the wild-type TSH receptor, as described above.

\section{Results}

We studied the ability of three TSH-LH/CG receptor chimeras to function in TSI and TBI assays. Each of these chimeras contain different, overlapping regions of the TSH receptor (15), and binds TSH with high affinity (Fig. 1). Only the chimera with TSH receptor domains ABC (TSH-LHR-6) responded to a series of IgG from patients with autoimmune thyroid disease selected to cover a wide range of TSI activities (Fig. 2). The chimeras with TSH receptor domains CD (TSHLHR-10) and DE (TSH-LHR-9) were unresponsive. The lack of response of chimera TSH-LHR-9 was anticipated because it fails to transduce a signal with TSH stimulation (15). Chimera TSH-LHR-10, however, does transduce a signal upon TSH binding. A different spectrum of responses was observed when the TSH-LH/CG chimeras were used in a TBI, rather than in a TSI, assay (Fig. 3). IgG from autoimmune thyroid disease patients' sera that competed for TSH binding to the wild-type TSH receptor were approximately equipotent in an assay using the TSH-LH/CG receptor chimera with the TSH receptor domains DE (TSH-LHR-9). Dramatically, these IgG did not inhibit TSH binding to the chimera with TSH receptor domains CD (TSH-LHR-10). When assayed with chimera TSH-LHR-6 (TSH receptor domains ABC), TBI activity was very weak relative to that in the assay with the wild-type TSH receptor, in contrast to the excellent functional response of this chimera to stimulatory IgG.

The divergence in the thyroid-stimulatory and TSH binding-inhibitory responses observed in the foregoing studies raised the possibility of the preferential binding of IgG with TSI activity to domains $\mathrm{ABC}$, and IgG with TBI activity to domains

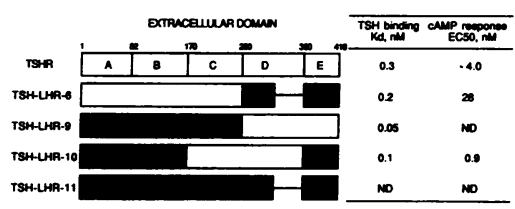

Figure 1. Summary of the structure and function of TSH-LH/CG chimeras used in this study, as previously reported in detail (15). The extracellular region of the TSH receptor was divided into five domains (A to $\mathrm{E}$ ). The open and black bars denote the human TSH and the rat LH/CG receptor sequences, respectively. Domain D in the LH/CG receptor is 50 amino acids shorter than its TSH receptor counterpart, as shown by the thin horizontal line. TSH-LHR-6 contains domains ABC (amino acids 1-260), TSH-LHR-9 contains domains DE (amino acids 261-418) and TSH-LHR-10 contains domains CD (171-360) of the TSH receptor extracellular domain. TSH-LHR-11 contains the entire extracellular region of the LH/CG receptor. EC50, concentration of TSH required for a half-maximal increase in cAMP generation. ND, not detectable. 


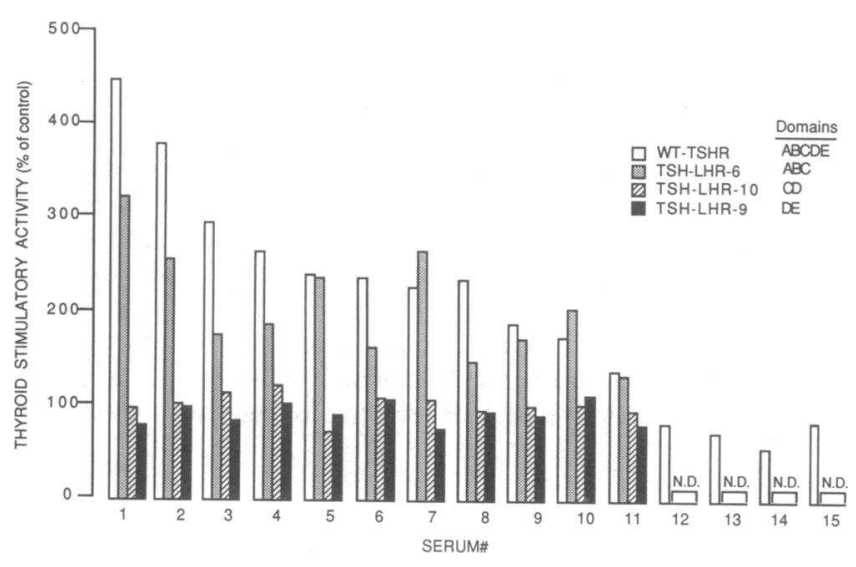

Figure 2. Comparison of thyroid-stimulatory activities in IgG from patients with autoimmune thyroid disease using $\mathrm{CHO}$ cells expressing the TSH receptor or TSH-LH/CG chimeras. IgG were selected to give a broad range of TSI activity. 4 IgG (IgG Nos. 12-15) were chosen on the basis of being nonstimulatory but able to inhibit TSH binding to the wild-type TSH receptor (see Fig. 3). Cell incubations and cAMP assays were performed as described in Methods. Data are expressed as a percentage of the mean of values obtained with IgG from three normal individuals when tested with each of the three chimeras and the wild-type receptor. Values $>2$ SD above the mean values with the normal IgG (range of $125-135 \%$ of control) were defined as positive. Each bar represents the mean of at least two different experiments, each experiment measured in duplicate dishes of cells. WT, wild-type; N.D., not done.

DE, of the TSH receptor. In order to test this hypothesis, chimeras with these TSH receptor domains were used to affinity purify TSH receptor antibodies from patients' IgG. The IgG used (Nos. 8, 9, and 10; Fig. 2) were selected on the basis of their stimulatory activity and their complete inability to inhibit TSH binding when tested with chimera TSH-LHR-6 (domains $\mathrm{ABC})$. Chimeras with TSH receptor domains $\mathrm{ABC}$ and $\mathrm{DE}$

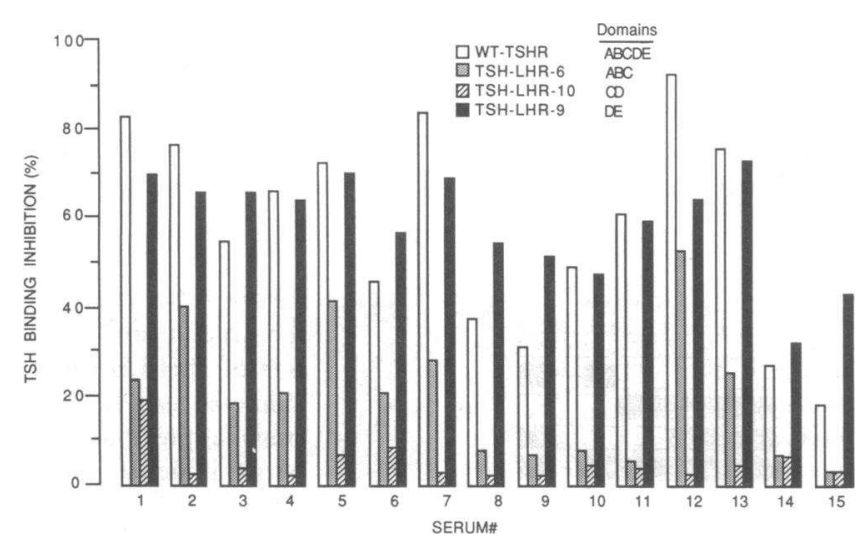

Figure 3. Comparison of TSH binding-inhibitory activity in IgG from patients with autoimmune thyroid disease using $\mathrm{CHO}$ cells expressing the TSH receptor or TSH-LH/CG chimeras. Incubations and TSH binding assays were performed as described in Methods. Data are expressed as follows: [1 - (radioactivity of test $\mathrm{IgG} /$ radioactivity of normal $\operatorname{lgG})] \times 100(\%)$. Values $>2$ SD above the mean of three normal IgGs (inhibition of 10-15\% of maximum TSH binding in the four different receptors) were defined as positive. Each bar represents the mean of at least two different experiments, each experiment measured in duplicate dishes of cells. WT, wild-type.

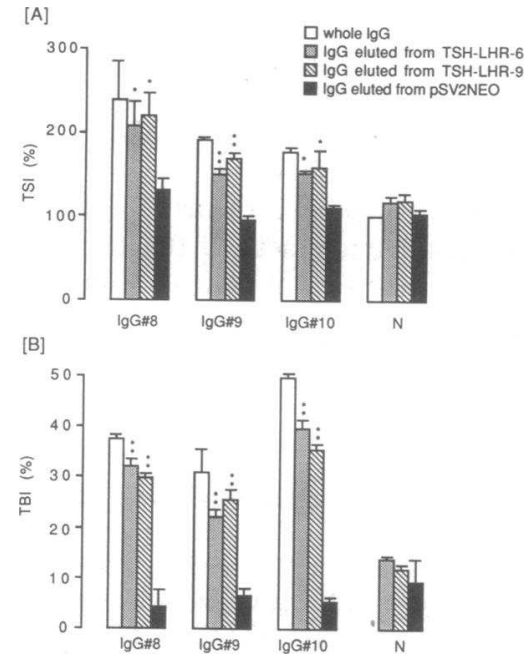

Figure 4. Immunoadsorption of IgG with thyroid-stimulatory and TSH binding-inhibitory activity using $\mathrm{CHO}$ cells expressing TSH-LH/CG receptor chimeras containing TSH receptor extracellular domains ABC (TSH-LHR-6) and DE (TSH-LHR-9). As a control, the indicated IgG (Nos. 8, 9, and 10; see Figs. 2 and 3) were also adsorbed to $\mathrm{CHO}$ cells transfected with $\mathrm{pSV}_{2} \mathrm{NEO}$. As a further control, IgG from normal individuals $(N)$ were also subjected to the same immunoadsorption procedure. The elution buffer containing the IgG was concentrated $\sim 15$-fold and then tested for both stimulatory $(A)$ and TSH binding-inhibitory $(B)$ activity using CHO cells expressing the wild-type TSH receptor (see Methods). TSI data are expressed as a percentage of values obtained with assay buffer alone. TBI data are expressed as follows: [1-(radioactivity of test $\mathrm{IgG} /$ radioactivity of assay buffer)] $\times 100(\%)$. Each bar represents the mean $\pm S E$ of data obtained in triplicate experiments. Significance of differences $(t$ test) between IgG adsorbed to the indicated chimeras and the $\mathrm{pSV}_{2} \mathrm{NEO}$ control; ${ }^{*} P<0.05,{ }^{* *} P<0.01$.

were equally effective in the affinity purification of both TSI and TBI activities when tested with the wild-type receptor (Fig. 4). As controls, $\mathrm{CHO}$ cells stably transfected with $\mathrm{pSV}_{2} \mathrm{NEO}$ could not affinity purify IgG with either TSI or TBI activity. A similar lack of adsorption was seen with a chimeric receptor (TSH-LHR-11; Fig. 1) containing the entire extracellular domain of the $\mathrm{LH} / \mathrm{CG}$ receptor (data not shown).

Finally, the interaction between the thyroid-stimulatory and TSH binding-inhibitory antibodies was examined (Table I). Two nonstimulatory IgG with potent TBI activity (IgG Nos. 12 and 13) inhibited the activity of stimulatory IgG (IgG Nos. 1 and 2) when tested with the wild-type TSH receptor. In contrast, these two inhibitory IgG had no effect on TSI activity when tested in chimera TSH-LHR- 6 that has only TSH receptor domains ABC. TSH-LHR-9 cannot be tested for potential inhibition of TSI activity because this receptor chimera cannot transduce a cAMP signal.

\section{Discussion}

Present evidence suggests that the sera of some patients with autoimmune thyroid disease contain a mixture of stimulatory or inhibitory TSH receptor antibodies $(1,7,20)$. Although the epitopes for these antibodies are unknown, the present concept is that they correspond to the TSH binding site on the TSH receptor. Contradictory data exist for and against this hypothesis. Evidence against the identity of the antibody and ligand binding sites on the TSH receptor includes data suggesting that thyroid-stimulatory and TSH binding-inhibitory antibodies do not compete with each other in terms of their ability to inhibit TSH binding to the TSH receptor (21). Further, there are reports purporting to indicate the generation of human monoclonal TSH receptor antibodies with separate thyroid-stimulatory 
Table I. Inhibition of the Activity of Thyroid-Stimulatory Antibodies by Nonstimulatory IgG with TSH Binding-Inhibitory Activity

\begin{tabular}{ccc}
\hline Receptor domains & WT-TSHR (ABCDE) & TSH-LHR-6 (ABC) \\
\hline Stimulatory IgG\#1 + pooled normal IgG & $228.4 \pm 11.9^{*}$ & $247.8 \pm 12.9$ \\
+ inhibitory IgG No. 12 & $142.4 \pm 9.1^{\ddagger}$ & $247.8 \pm 8.6$ \\
+ inhibitory IgG No. 13 & $124.0 \pm 6.1^{\ddagger}$ & $239.2 \pm 6.2$ \\
Stimulatory IgG\#2 + pooled normal IgG & $219.0 \pm 8.8$ & $182.0 \pm 0.6$ \\
+ inhibitory IgG No. 12 & $104.0 \pm 10.8^{\ddagger}$ & $195.6 \pm 11.8$ \\
+ inhibitory IgG No. 13 & $137.5 \pm 4.8^{\ddagger}$ & $213.0 \pm 19.7$
\end{tabular}

IgG were tested with stably-transfected CHO cells expressing either the wild-type TSH receptor (WT-TSHR) or the TSH-LH/CG chimeric receptor (TSH-LHR-6) containing domains ABC (amino acids 1-260) of the TSH receptor. ${ }^{*}$ Mean \pm SE of data from triplicate experiments; ${ }^{\ddagger} P<0.01$, inhibition compared with pooled normal IgG $(t$ test).

and TSH binding-inhibitory activities (22-24), but none of these antibodies have been proven to be against the TSH receptor. The reported ability of IgG from patients with autoimmune thyroid disease to immunoprecipitate TSH - TSH receptor complexes (25-28) would also support the existence of separate binding sites for TSH receptor antibodies and TSH. However, these findings have been disputed (1).

Other data support the contrary thesis, namely that the antibody and ligand binding sites are the same. Thus, IgG from almost all patients with active Graves' disease have TSH binding-inhibitory activity (29), although it is not proven that this activity is inherent to the same IgG molecules with thyroidstimulatory activity. Further, inhibitory antibodies are reported to become stimulatory after they are bound by antiIgG (30).

This descriptive era is now drawing to a close with the recent advances in defining epitopes and ligand binding sites at the molecular level. Epitopes typically contain 14-21 amino acids contributed to by 2-4 discontinuous regions in the primary amino acid sequence $(17,18)$. There is recent evidence for the localization of a number of these TSH receptor autoantibody binding regions. Thus, deletional and nonhomologous substitutions of amino acids 38-45 in the TSH receptor suggest that this segment may be important in TSH and thyroid-stimulatory antibody functional activity (31). In these studies, however, the three-dimensional integrity of the TSH receptor could not be confirmed. Antibody binding to synthetic peptides suggests that TSH receptor amino acids 32-56 (overlapping with the above mentioned region), 309-317, and 123-131 may also contribute to the TSH receptor epitopes $(32,33)$. While these amino acid sequences may be part of the TSH binding sites, the binding affinity of antibodies for synthetic peptides is generally low, and the data cannot be regarded as definitive.

In this study, wild-type TSH receptor (8) and TSH-LH/CG receptor extracellular domain chimeras (15) were used to compare the binding domain for TSH with those for thyroid-stimulatory and TSH binding-inhibitory autoantibodies. The proven preservation of chimera functional integrity makes the data more definitive than those obtained using deletional/nonhomologous mutagenesis or synthetic peptides. A recognized limitation to the chimeric approach, however, is that the binding or function of an antibody may not be altered if the homologous regions substituted have functions common to both receptors. Both the TSH and LH/CG receptors interact with the common alpha-subunit of the glycoprotein hormones. Using TSH-LH/ CG receptor chimeras, it may, therefore, not be possible to identify the epitopes for antibodies that preferentially bind to alpha-subunit binding site(s). However, the inability of the chimera with the entire LH/CG receptor extracellular domain (TSH-LHR-11) to affinity purify TSH receptor autoantibodies suggests the lesser importance of TSH alpha-subunit binding site(s) in autoantibody binding to the TSH receptor.

Two conclusions can be drawn from our data (shown schematically in Fig. 5). First, TSH receptor antibodies bind to regions in both domains $\mathrm{ABC}$ and $\mathrm{DE}$ of the TSH receptor. This phenomenon is similar to that previously demonstrated for TSH binding to the receptor (15) and presumably occurs because segments in these domains are brought into apposition by folding of the globular receptor protein. The epitopes for stimulatory and inhibitory antibodies must be included in both domains $\mathrm{ABC}$ and $\mathrm{DE}$ of the TSH receptor because chimeras TSH-LHR-6 (TSH receptor domains ABC) and TSH-LHR-9 (TSH receptor domains DE) are both capable of affinity purifying these antibodies.

A second conclusion from our data is that the epitopes for TSH receptor antibodies are unlikely to be identical to the TSH binding site. Evidence for this conclusion is that chimera TSHLHR-10, which displays functional, high affinity TSH binding, does not respond functionally to TSI; further, TBI does not compete for TSH binding to this mutant receptor. The nonidentity in the hormone and antibody binding sites is likely to be inherent primarily in domains $\mathrm{ABC}$, rather than in domains $\mathrm{DE}$, of the receptor. This is because TSH receptor antibodies compete less well for TSH binding to chimera TSH-LHR-6 (TSH receptor domains ABC) than to the wild-type TSH receptor. In contrast, TSH receptor antibodies compete approximately equally for TSH binding to chimera TSH-LHR-9 (TSH receptor domains DE) and to the wild-type TSH receptor.

Not only do the hormone and antibody binding sites ap-

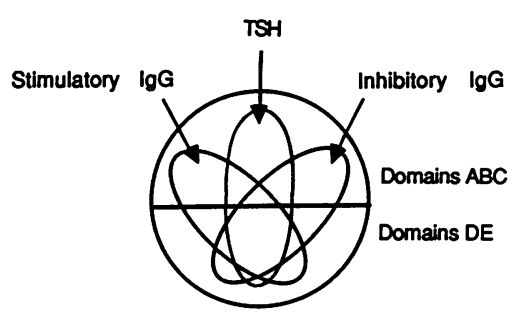

Figure 5. Schematic representation of the TSH and TSH receptor autoantibody binding domains. The diagram represents a working hypothesis based on the present data, as well as on previous data defining TSH binding sites

on the TSH receptor $(15,16)$. TSH binding sites and the epitopes for the stimulatory and the inhibitory autoantibodies closely overlap each other in domains DE, but not in domains $\mathrm{ABC}$ of the TSH receptor extracellular region. 
pear to differ in TSH receptor domains ABC, but our data also suggest that the epitopes for stimulatory and inhibitory antibodies are not identical within domains ABC. This is because the "pure" inhibitory antibodies (sera Nos. 12 and 13) inhibit TSI stimulation of cAMP generation by the wild-type TSH receptor, but not by chimera TSH-LHR-6 (domains ABC). That is, when TSH receptor domains DE are absent (TSH-LHR-6), the different types of antibodies do not compete with each other. Variability in TSH receptor antibody competition for TSH binding to chimera TSH-LHR-6 suggests that, even within the population of inhibitory antibodies, there may be heterogeneity in the antibody binding site(s) in TSH receptor domains ABC.

It must be acknowledged that the foregoing interpretations rest on the premise that antibody inhibition of TSH binding reflects at least partial overlap of their respective binding sites rather than steric, or allo-steric, effects of antibody on TSH binding. We also cannot exclude the possibility that stimulatory and inhibitory TSH receptor antibodies bind to the same epitope in domains $A B C$, but with different affinities. In this case, TSH binds to chimera TSH-LHR- 6 with higher affinity than do the TSH receptor autoantibodies.

In conclusion, these data provide the first indication at the molecular level that the epitopes for TSH receptor antibodies may not be identical to the TSH binding sites on the TSH receptor. Further mutagenesis studies may be helpful for fine epitope mapping of TSH receptor autoantibodies.

\section{Acknowledgments}

We thank Professor Shigenobu Nagataki and Dr. Motomori Izumi, Nagasaki, Japan, Dr. Sebastiano Filetti, Catania, Italy, and Dr. Juan Carlos Tercera, Nichols Institute, San Juan Capistrano, California for providing serum samples, and Ms. Carmela Filamor for her expert administrative assistance.

This research was supported by National Institutes of Health grants DK-19289, DK-36182, and the Research Service of the Veterans Administration.

\section{References}

1. Rees Smith, B., S. M. McLachlan, and J. Furmaniak. 1988. Autoantibodies to the thyrotropin receptor. Endocr. Rev. 9:106-121.

2. Kasagi, K., J. Konishi, K. Arai, T. Misaki, Y. Iida, K. Endo, and K. Torizuka. 1986. A sensitive and practical assay for thyroid-stimulating antibodies using crude immunoglobulin fractions precipitated with polyethylene glycol. $J$. Clin. Endocrinol. \& Metab. 62:855-862.

3. Hinds, W. E., N. Takai, B. Rapoport, S. Filetti, and O. H. Clark. 1981. Thyroid-stimulating immunoglobulin bioassay using cultured human thyroid cells. J. Clin. Endocrinol. \& Metab. 52:1204-1210.

4. Rees Smith, B., and R. Hall. 1974. Thyroid-stimulating immunoglobulins in Graves' disease. Lancet. 427-431.

5. Zakarija, M., J. M. McKenzie, and M. S. Eidson. 1990. Transient neonatal hypothyroidism: characterization of maternal antibodies to the thyrotropin receptor. J. Clin. Endocrinol. \& Metab. 70:1239-1246.

6. Filetti, S., D. Foti, G. Costante, and B. Rapoport. 1991. Recombinant human TSH receptor in a radioreceptor assay for the measurement of TSH receptor autoantibodies. J. Clin. Endocrinol. \& Metab. 72:1096-1101.

7. Zakarija, M., J. M. McKenzie, and D. S. Munro. 1983. Immunoglobulin G inhibitor of thyroid-stimulating antibody is a cause of delay in the onset of neonatal Graves' disease. J. Clin. Invest. 72:1352-1356.

8. Nagayama, Y., K. D. Kaufman, P. Seto, and B. Rapoport. 1989. Molecular cloning, sequence and functional expression of the cDNA for the human thyrotropin receptor. Biochem. Biophys. Res. Commun. 165:1184-1190.

9. Libert, F., A. Lefort, C. Gerard, M. Parmentier, J. Perret, M. Ludgate, J. E. Dumont, and G. Vassart. 1989. Cloning, sequencing and expression of the human thyrotropin (TSH) receptor: evidence for binding of autoantibodies. Biochem. Biophys. Res. Commun. 165:1250-1255.
10. Misrahi, M., H. Loosfelt, M. Atger, S. Sar, A. Guiochon-Mantel, and E. Milgrom. 1990. Cloning, sequencing and expression of human TSH receptor. Biochem. Biophys. Res. Commun. 166:394-403.

11. Frazier, A. L., L. S. Robbins, P. J. Stork, R. Sprengel, D. L. Segaloff, and R. D. Cone. 1990. Isolation of TSH and LH/CG receptor CDNAs from human thyroid: regulation by tissue specific splicing. Mol. Endocrinol. 90:1264-1276.

12. McFarland, K. C., R. Sprengel, H. S. Phillips, M. Kohler, N. Rosemblit, K. Nikolics, D. L. Segaloff, and P. H. Seeburg. 1989. Lutropin-choriogonadotropin receptor: an unusual member of the $G$ protein-coupled receptor family. Science (Wash. DC). 245:494-499.

13. Loosfelt, H., M. Misrahi, M. Atger, R. Salesse, M. T. Vu Hai-Luu Thi, A. Jolivet, A. Guiochon-Mantel, S. Sar, B. Jallal, J. Garnier, and E. Milgrom. 1989. Cloning and sequencing of porcine LH-hCG receptor cDNA: variants lacking transmembrane domain. Science (Wash. DC). 245:525-528.

14. Sprengel, R., T. Braun, K. Nikolics, D. L. Segaloff, and P. H. Seeburg. 1990. The testicular receptor for follicle stimulating hormone: structure and functional expression of cloned cDNA. Mol. Endocrinol. 4:525-530.

15. Nagayama, Y., H. L. Wadsworth, G. D. Chazenbalk, D. Russo, P. Seto, and B. Rapoport. 1991. Thyrotropin-luteinizing hormone/chorionic gonadotropin receptor extracellular domain chimeras as probes for TSH receptor function. Proc. Natl. Acad. Sci. USA. 88:902-905.

16. Nagayama, Y., D. Russo, G. D. Chazenbalk, H. L. Wadsworth, and B. Rapoport. 1990. Extracellular domain chimeras of the TSH and LH/CG receptors reveal the mid-region (amino acids 171-260) to play a vital role in high affinity TSH binding. Biochem. Biophys. Res. Commun. 173:1150-1156.

17. Laver, W. G., G. M. Air, R. G. Webster, and S. J. Smith-Gill. 1990. Epitopes on protein antigens: misconceptions and realities. Cell. 61:553-556.

18. Davies, D. R., and E. Padlan. 1990. Antibody-Antigen Complexes. Annu. Rev. Biochem. 59:439-473.

19. Rapoport, B., S. Filetti, N. Takai, P. Seto, and G. Halverson. 1982. Studies on the cyclic AMP response to thyroid stimulating immunoglobulin (TSI) and thyrotropin (TSH) in human thyroid cell monolayers. Metabolism. 31:11591167.

20. Zakarija, M., A. Garcia, and J. M. McKenzie. 1985. Studies on multiple thyroid cell membrane-directed antibodies in Graves' disease. J. Clin. Invest. 76:1885-1891.

21. Morita, S., M. Izumi, and S. Nagataki. 1986. Interactions between TSH binding inhibiting - and adenylate cyclase stimulating - antibodies in Graves' disease. Acta Endocrinologica. 112:517-522.

22. Ealey, P. A., L. D. Kohn, R. P. Ekins, and N. J. Marshall. 1984. Characterization of monoclonal antibodies derived from lymphocytes from Graves' disease patients in a cytochemical bioassay for thyroid stimulators. J. Clin. Endocrinol. \& Metab. 58:909-914.

23. Valente, W. A., P. Vitti, Z. Yavin, E. Yavin, C. M. Rotella, E. F. Grollman, R. S. Toccafondi, and L. D. Kohn. 1982. Monoclonal antibodies to the thyrotropin receptor: stimulating and blocking antibodies derived from the lymphocytes of patients with Graves disease. Proc. Natl. Acad. Sci. USA. 79:6680 6684 .

24. Yokoyama, N., M. Izumi, S. Katamine, and S. Nagataki. 1987. Heterogeneity of Graves' immunoglobulin G: comparison of thyrotropin receptor antibodies in serum and in culture supernatants of lymphocytes transformed by EpsteinBarr virus infection. J. Clin. Endocrinol. \& Metab. 64:215-218.

25. Heyma, P., and L. C. Harrison. 1984. Precipitation of the thyrotropin receptor and identification of thyroid autoantigens using Graves' disease immunoglobulin. J. Clin. Invest. 74:1090-1097.

26. de Bruin, T. W. A., D. van der Heide, and M. C. Krol. 1983. Anti-thyrotropin receptor antibodies in Graves' disease as demonstrated directly by immunoprecipitation assay. Acta Endocrinologica. 102:49-56.

27. de Bruin, T. W. A., D. van der Heide, A. Querido, and M. C. Krol. 1984. Direct and quantitative measurement by immunoprecipitation assay of antithyrotropin receptor antibodies in sera of patients with Graves' disease. Clin. Endocrinol. 20:143-151.

28. de Bruin, T. W. A., L. E. Braverman, and R. S. Brown. 1990. Heterogeneity of TSH receptor-binding antibodies in Hashimoto's thyroiditis and Graves' disease. Am. J. Med. Sci. 299:291-297.

29. Shewring, G. A., and B. Rees Smith. 1982. An improved radioreceptor assay for TSH receptor antibodies. Clin. Endocrinol. 17:409-417.

30. Amino, N., Y. Watanabe, H. Tamaki, Y. Iwatani, and K. Miyai. 1987. In-vitro conversion of blocking type anti-TSH receptor antibody to the stimulating type by anti-human IgG antibodies. Clin. Endocrinol. 27:615-624.

31. Wadsworth, H. L., G. D. Chazenbalk, Y. Nagayama, D. Russo, and B. Rapoport. 1990. An insertion in the human thyrotropin receptor critical for high affinity hormone binding. Science (Wash. DC). 249:1423-1425.

32. Murakami, M., and M. Mori. 1990 . Identification of immunogenic regions in human thyrotropin receptor for immunoglobulin $\mathbf{G}$ of patients with Graves' disease. Biochem. Biophys. Res. Commun. 171:512-518.

33. Piraphatdist, T., H. Sugawa, D. Inoue, T. Enomoto, T. Mori, and H. Imura. 1990. Possible binding site of thyrotropin binding inhibitor immunoglobulin (TBII) on the thyrotopin (TSH) receptor, which is different from TSH binding site. Biochem. Biophys. Res. Commun. 172:529-536. 